\title{
Comparative analysis of complete mitochondrial genome sequences confirms independent origins of plant-parasitic nematodes
}

Tahera Sultana ${ }^{1}$, Jiyeon Kim²${ }^{2}$, Sang-Hwa Lee ${ }^{2}$, Hyerim Han³ ${ }^{3}$ Sanghee Kim ${ }^{4}$, Gi-Sik Min ${ }^{1}$, Steven A Nadler ${ }^{5}$ and Joong-Ki Park $2,6^{*}$

\begin{abstract}
Background: The nematode infraorder Tylenchomorpha (Class Chromadorea) includes plant parasites that are of agricultural and economic importance, as well as insect-associates and fungal feeding species. Among tylenchomorph plant parasites, members of the superfamily Tylenchoidea, such as root-knot nematodes, have great impact on agriculture. Of the five superfamilies within Tylenchomorpha, one (Aphelenchoidea) includes mainly fungal-feeding species, but also some damaging plant pathogens, including certain Bursaphelenchus spp. The evolutionary relationships of tylenchoid and aphelenchoid nematodes have been disputed based on classical morphological features and molecular data. For example, similarities in the structure of the stomatostylet suggested a common evolutionary origin. In contrast, phylogenetic hypotheses based on nuclear SSU ribosomal DNA sequences have revealed paraphyly of Aphelenchoidea, with, for example, fungal-feeding Aphelenchus spp. within Tylenchomorpha, but Bursaphelenchus and Aphelenchoides spp. more closely related to infraorder Panagrolaimomorpha. We investigated phylogenetic relationships of plant-parasitic tylenchoid and aphelenchoid species in the context of other chromadorean nematodes based on comparative analysis of complete mitochondrial genome data, including two newly sequenced genomes from Bursaphelenchus xylophilus (Aphelenchoidea) and Pratylenchus vulnus (Tylenchoidea).

Results: The complete mitochondrial genomes of B. xylophilus and P. vulnus are 14,778 bp and 21,656 bp, respectively, and identical to all other chromadorean nematode mtDNAs in that they contain 36 genes (lacking atp8) encoded in the same direction. Their mitochondrial protein-coding genes are biased toward use of amino acids encoded by T-rich codons, resulting in high A+T richness. Phylogenetic analyses of both nucleotide and amino acid sequence datasets using maximum likelihood and Bayesian methods did not support B. xylophilus as most closely related to Tylenchomorpha (Tylenchoidea). Instead, B. xylophilus, was nested within a strongly supported clade consisting of species from infraorders Rhabditomorpha, Panagrolaimomorpha,

Diplogasteromorpha, and Ascaridomorpha. The clade containing sampled Tylenchoidea (P. vulnus, H. glycines, and $R$. similis) was sister to all analyzed chromadoreans. Comparison of gene arrangement data was also consistent with the phylogenetic relationships as inferred from sequence data. Alternative tree topologies depicting a monophyletic grouping of B. xylophilus (Aphelenchoidea) plus Tylenchoidea, Tylenchoidea plus Diplogasteromorpha (Pristionchus pacificus), or B. xylophilus plus Diplogasteromorpha were significantly worse interpretations of the mtDNA data. (Continued on next page)
\end{abstract}

\footnotetext{
* Correspondence: jkpyou@chungbuk.ac.kr

${ }^{2}$ Graduate Program in Cell Biology and Genetics, College of Medicine,

Chungbuk National University, Cheongju 361-763, Republic of Korea

${ }^{6}$ Graduate Program in Cell Biology and Genetics and Department of

Parasitology, College of Medicine, Chungbuk National University, Cheongju

361-763, Republic of Korea

Full list of author information is available at the end of the article
}

\section{Biomed Central}

(c) 2013 Sultana et al.; licensee BioMed Central Ltd. This is an Open Access article distributed under the terms of the Creative Commons Attribution License (http://creativecommons.org/licenses/by/2.0), which permits unrestricted use, distribution, and reproduction in any medium, provided the original work is properly cited. 
(Continued from previous page)

Conclusions: Phylogenetic trees inferred from nucleotide and amino acid sequences of mtDNA coding genes are in agreement that B. xylophilus (the single representative of Aphelenchoidea) is not closely related to Tylenchoidea, indicating that these two groups of plant parasites do not share an exclusive most recent common ancestor, and that certain morphological similarities between these stylet-bearing nematodes must result from convergent evolution. In addition, the exceptionally large mtDNA genome size of $P$. vulnus, which is the largest among chromadorean nematode mtDNAs sequenced to date, results from lengthy repeated segments in non-coding regions.

Keywords: Plant parasitism, Tylenchomorpha, Chromadorea, Nematoda, Mitochondrial genome, Molecular phylogeny

\section{Background}

Nematodes are among the most common, abundant and ecologically diverse animal groups. Free-living species inhabit almost every environment, and are extremely abundant in soils and aquatic sediments, both freshwater and marine $[1,2]$. Most nematode diversity is represented by these free-living species [3]. Nematode parasites of plants and animals are also frequently encountered, and cause reductions in agricultural productivity, and disease in humans, domestic animals and wildlife [4]. Plant-parasitic nematodes attack a wide variety of commercial crops, mainly causing damage to root tissues [5] that impacts on the physiology of the host plant [6], particularly water transport. Plant parasites are usually microscopic, and may feed on plant tissues as ectoparasites or endoparasites, depending on the species. Among the most remarkable specializations of plant parasites are sedentary endoparasites that induce nurse cells in host plant roots that serve as metabolic sinks and nematode feeding sites, sustaining the sedentary female nematode during its lifetime in the host tissue. Other plant-parasitic species have more diverse feeding habits. For example, the pine wilt nematode Bursaphelenchus xylophilus, which is transmitted by wood-boring beetles, has both phytophagous and mycophagous phases in its life history.

Molecular phylogenies based on SSU rDNA [7-11] indicate that three traditional orders of plant parasites, Dorylaimida Pearse 1942, Triplonchida Cobb 1920, and Tylenchida Thorne 1949 evolved independently. Modern taxonomic systems for nematodes [12,13] are mainly based on the phylogenetic framework provided by SSU rDNA in combination with new interpretations of developmental and morphological features. In the taxonomy of De Ley and Blaxter [12,13], which is used herein, orders Dorylaimida and Triplonchida (within class Enoplea) are retained, whereas the phylogenetic framework guides taxonomic reorganization of a diverse assemblage of species (free-living and parasitic) within suborder Tylenchina (order Rhabditida, class Chromadorea). Within Tylenchina, the infraorder Tylenchomorpha includes stylet-bearing nematodes with representatives that are plant-parasites, insect associates or parasites (e.g., Sphaerulariidae), and fungal feeders. Several of the superfamilies within Tylenchomorpha include important plant pathogens $[3,14]$, particularly Tylenchoidea (which includes rootknot and lesion nematodes, among others), but also Aphelenchoidea, the superfamily that includes insect associates, fungivores, and plant-associates that in some cases are either direct causative agents of plant disease (B. xylophilus), or through fungal feeding are associated with root disease (e.g., Aphelenchus avenae). The relationship and taxonomy of groups now classified as Tylenchomorpha, and specifically the relationship of aphelenchs to other stylet-bearing Tylenchina, has been a topic of debate among nematode taxonomists for several decades.

Some arguments for a close relationship between aphelenchs and Tylenchomorpha have been based on morphology, for example, the highly similar protrusible stylets (stomatostylets) in these taxa [15], or aspects of female genital structure [16]. However, Siddiqi [14] suggested that the similar stylets of these nematodes arose independently, with the stylet of aphelenchs derived from diplogasteromorph ancestors, thus rejecting the concept of their close evolutionary relationship. Siddiqi [14] recognized aphelenchs as a separate evolutionary group [17-19].

In recent years, phylogenetic relationships inferred from SSU rDNA sequences [7-11] have provided an alternative framework for nematode classification. Representatives of Tylenchomorpha including certain aphelenchs (Aphelenchidae) comprised a clade, with the fungivorous Aphelenchidae typically the sister group to plant-parasitic tylenchomorphs. However, the Aphelenchoidea were not monophyletic [9-11], with plant pathogens such as Aphelenchoides spp. and Bursaphelenchus spp. (Aphelenchoididae) either unresolved among Tylenchina [11] or more closely related to Panagrolaimomorpha, but in the latter case with support levels varying substantially, depending on inference method $[9,10]$. Recent fine structure reconstructions of the pharynx also call into question the monophyly of Aphelenchoidea, revealing lack of cellular 
homology underlying structures previously assumed to unite Aphelenchidae and Aphelenchoididae [20]. It is unclear if artefacts such as base compositional bias or long-branch-attraction may be influencing the position of Bursaphelenchus spp. and other Aphelenchoididae in SSU trees, but this potential caveat has been suggested as one possible explanation for non-monophyly [12]. For this reason, independent phylogenetic evidence from other gene loci is needed to test this and other hypotheses of nematode relationships.

As in many other metazoan groups, comparative analysis of nematode mitochondrial $(\mathrm{mt})$ genome information (nucleotide and amino acid sequences, and gene arrangement) appears useful for resolving relationships at different divergence levels [21-24]. To date, 63 complete $\mathrm{mt}$ genomes have been reported for nematodes ( 52 chromadoreans and 11 enopleans), however, taxon sampling is biased toward parasites of vertebrates. Despite their importance to agriculture, Tylenchomorpha are undersampled for complete mitochondrial genomes. Published reports include the complete sequence of the burrowing nematode [25] Radopholus similis (Tylenchoidea, Pratylenchidae), and partial genome, but complete coding sequences of the soybean cyst nematode [26] Heterodera glycines (Tylenchoidea, Hoplolaimidae). However, the focus of these studies has been on idiosyncratic features of the $\mathrm{mt}$ sequences and not phylogenetic context. In this study, we determined the complete mitochondrial DNA sequences of Bursaphelenchus xylophilus, the first representative of the Aphelenchoidea and Pratylenchus vulnus, the second representative of the family Pratylenchidae, respectively, and used these data for inferring phylogenetic relationships among the major groups of chromadoreans.

\section{Results and discussion}

\section{Gene contents and organization}

The complete mitochondrial genomes of B. xylophilus (GenBank accession number: GQ332424) and P. vulnus (GenBank accession number GQ332425) are 14,778 bp and 21,656 bp, respectively. The mtDNA of $P$. vulnus is the largest among chromadorean nematode mtDNAs published to date. It is much larger than Radopholus similis $(16,791 \mathrm{bp})$, the first complete mtDNA for Tylenchoidea [25], and P. vulnus is third largest among all nematodes reported to date, following two Mermithida, Romanomermis culicivorax (26,194 bp) and Hexamermis agrotis (24,606 bp). Unlike enopleans, the mtDNA genomes of chromadorean nematodes do not normally exceed $17 \mathrm{~kb}$. The exception is the soybean cyst nematode Heterodera glycines that is estimated to have a 21-22 kbcircular mtDNA chromosome [26]. The remarkably large size of $P$. vulnus mtDNA is due to abnormally lengthy noncoding regions that harbor tandemly repeated sequences. This feature was also reported for the root-knot nematode
Meloidogyne javanica (Tylenchoidea), which contains a $7 \mathrm{~kb}$ control region with different numbers of tandemly repeated sequence units [27]. In some Enoplea (mermithids), size variation ranging from 19 to $34 \mathrm{~kb}$ is relatively common and is attributed to a 'hypervariable' segment that includes both coding and putative nonfunctional regions (see [28] for more details). The complete mitochondrial genomes of B. xylophilus (Figure 1A) and P. vulnus (Figure 1B) contain 36 genes that comprise 12 protein-coding genes (PCGs) but lacking atp8, 22 tRNA and 2 rRNA genes, all encoded in the same direction. This gene content is common to all other nematode mtDNAs so far sequenced, except for Trichinella spiralis (Enoplea) in which atp8 is also encoded [29]. The details of gene order and size for mtDNA of B. xylophilus and P. vulnus are shown in Table 1. The nucleotide composition of the mtDNA genome of each species has a strong bias toward A+T-richness with overall content of $83.5 \%$ in B. xylophilus $(51.7 \% \mathrm{~T}, 31.8 \% \mathrm{~A}, 11.1 \% \mathrm{G}$, and $5.4 \% \mathrm{C})$ and $73.9 \%$ in P. vulnus $(42.1 \% \mathrm{~T}, 31.8 \% \mathrm{~A}, 16.3 \% \mathrm{G}$, and $9.8 \% \mathrm{C})$, respectively (Table 2). The $\mathrm{A}+\mathrm{T}$ richness in these two species is related to the propensity for high frequency use of T-rich and/or A-rich codons in their protein-coding genes and higher $\mathrm{A}+\mathrm{T}$ content in non-coding regions (see following section).

\section{Protein-coding genes (PCGs)}

Twelve PCGs were identified from both species, ranging from $234 \mathrm{bp}$ (nad4L) to 1,569 bp (nad5) for B. xylophilus and from $231 \mathrm{bp}$ (nad4L) to 1,533 bp (cox1) for P. vulnus. Total length of the 12 PCGs of B. xylophilus mtDNA is $10,182 \mathrm{bp}$, accounting for $68.9 \%$ of its total mtDNA genome length. This value is slightly lower than most chromadoreans, such as Caenorhabditis briggsae (71.4\%), Ascaris suum (72.8\%) and Anisakis simplex (73.8\%). In contrast, total length of the 12 PCGs of P. vulnus mtDNA (10,002 bp) accounts for less than half (46.2\%) of its entire genome length. This lowered proportion of PCG sequence in $P$. vulnus is due to extraordinarily lengthy non-coding regions. This is very uncommon in other chromadorean nematode mtDNAs except for Heterorhabditis bacteriophora (56.84\%), but known for enoplean mitochondrial genomes, for example, Hexamermis agrotis (40.2\%), and Romanomermis culicivorax (37.9\%).

Out of 12 PCGs of B. xylophilus mtDNA, nine (cox1cox3, nad1-nad3, nad5, nad6 and atp6) are inferred to use ATT as the start codon, whereas three (nad4, nad4L and $c o b$ ) start with ATA (Table 1). Although ATG is known to be the most commonly used initiation codon for mitochondrial PCGs [30], use of others such as TTG is very common in some other nematode mtDNAs, including Anisakis simplex (9 of 12 genes) and Enterobius vermicularis (8 of 12 genes). Out of 12 P. vulnus PCGs, six (cox1-cox3, nad2, nad4, and $c o b)$ are inferred to use 


\section{(A)}
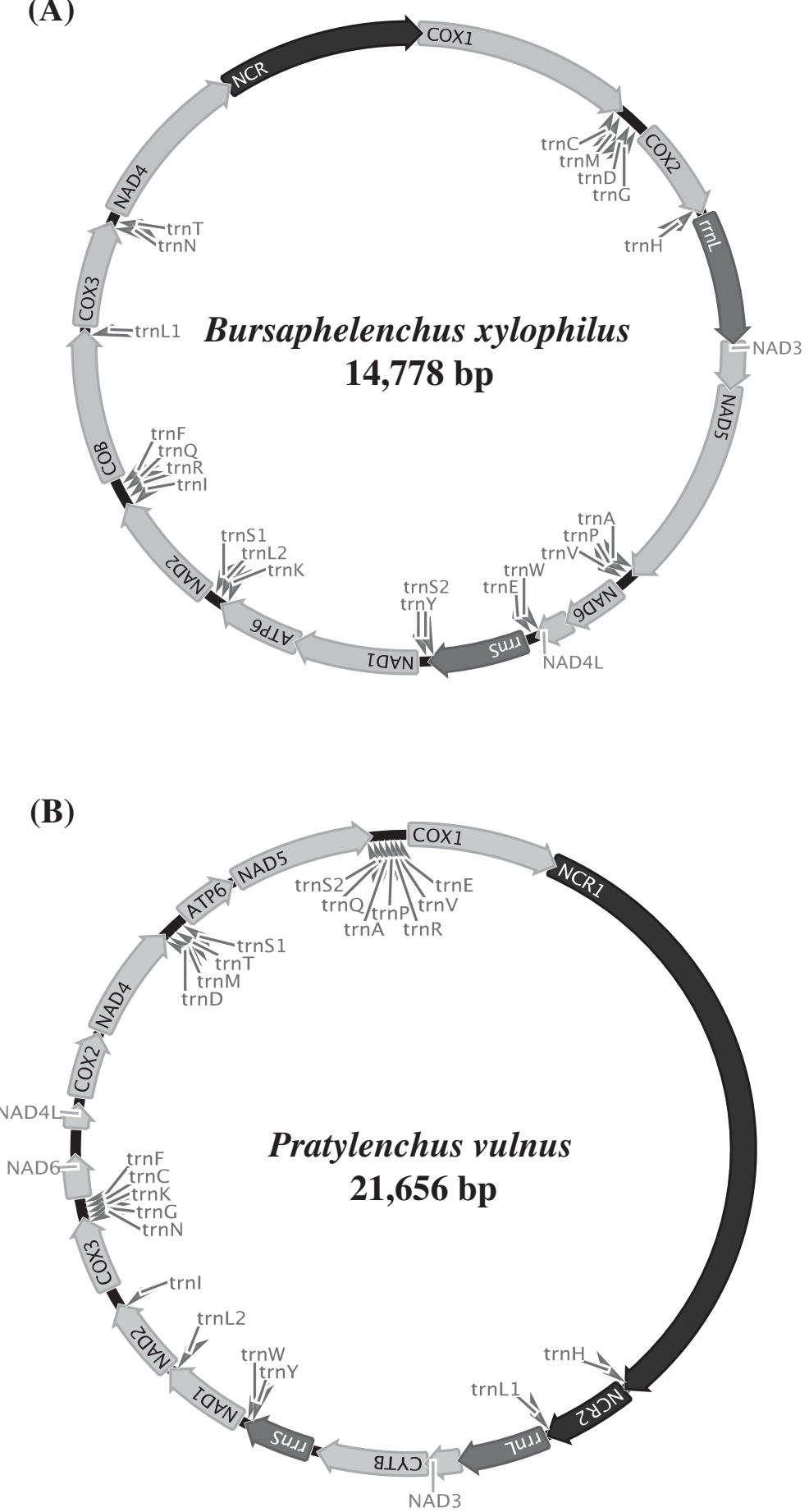

Figure 1 Circular gene maps of the complete mitochondrial genome for Bursaphelenchus xylophilus (A) and Pratylenchus vulnus (B). All genes are encoded in the same direction and 22 tRNA genes are designated by a single-letter abbreviation. The two leucine and two serine tRNA genes are labeled, according to their anticodon sequence, as L1 (trnL-uag), L2 (trnL-uaa), S1 (trnS-ucu), and S2 (trnS-uga), respectively. 
Table 1 The mitochondrial genome organization of Bursaphelenchus xylophilus (Bx) and Pratylenchus vulnus (Pv)

\begin{tabular}{|c|c|c|c|c|c|c|c|c|c|}
\hline \multicolumn{5}{|c|}{ Bursaphelenchus xylophilus } & \multicolumn{5}{|c|}{ Pratylenchus vulnus } \\
\hline Gene & $\begin{array}{l}\text { Positions and lengths } \\
\text { of nucleotide } \\
\text { sequences }\end{array}$ & $\begin{array}{l}\text { No. of } \\
\text { nt } \\
\text { (bp) }\end{array}$ & $\begin{array}{l}\text { Initiation and } \\
\text { termination } \\
\text { codons }\end{array}$ & $\begin{array}{l}\text { Intergenic } \\
\text { sequence }\end{array}$ & Gene & $\begin{array}{l}\text { Positions and lengths } \\
\text { of nucleotide } \\
\text { sequences }\end{array}$ & $\begin{array}{l}\text { No. of } \\
\text { nt } \\
\text { (bp) }\end{array}$ & $\begin{array}{l}\text { Initiation and } \\
\text { termination } \\
\text { codons }\end{array}$ & $\begin{array}{l}\text { Intergenic } \\
\text { sequence }\end{array}$ \\
\hline $\operatorname{cox} 1$ & $1-1563$ & 1563 & ATT/TAA & 11 & $\operatorname{cox} 1$ & $1-1533$ & 1533 & ATA/TAA & $7^{*}$ \\
\hline $\operatorname{trn} C$ & $1575-1628$ & 54 & & 5 & NCR1 & $1534-8380$ & 6847 & & \\
\hline $\operatorname{trn} M$ & $1634-1687$ & 54 & & 20 & $\operatorname{trnH}$ & $8381-8434$ & 54 & & \\
\hline $\operatorname{trn} D$ & $1708-1762$ & 55 & & 3 & NCR2 & 8435-9335 & 901 & & \\
\hline $\operatorname{trn} G$ & $1766-1819$ & 54 & & & $\operatorname{trnL1}$ & 9336-9393 & 58 & & 2 \\
\hline $\cos 2$ & $1820-2509$ & 690 & ATT/TAG & -2 & $r r n L$ & 9396-10290 & 895 & & 21 \\
\hline $\operatorname{trnH}$ & $2508-2562$ & 55 & & & nad3 & $10312-10641$ & 330 & ATT/TAG & 9 \\
\hline$r r n L$ & 2563-3510 & 948 & & & $c o b$ & 10651-11757 & 1107 & ATA/TAG & 123 \\
\hline nad3 & $3511-3840$ & 330 & ATT/TAA & 1 & $r r n s$ & $11881-12566$ & 686 & & \\
\hline nad5 & $3842-5410$ & 1569 & ATT/TAA & -1 & $\operatorname{trn} Y$ & $12567-12620$ & 54 & & \\
\hline $\operatorname{trn} A$ & $5410-5464$ & 55 & & & $\operatorname{trn} W$ & $12621-12676$ & 56 & & \\
\hline $\operatorname{trn} P$ & $5465-5521$ & 57 & & & nad1 & 12677-13549 & 873 & TTG/TAA & 1 \\
\hline $\operatorname{trn} V$ & $5522-5578$ & 57 & & & $\operatorname{trn} L 2$ & 13551-13606 & 56 & & 1 \\
\hline nad6 & $5579-6013$ & 435 & ATT/TAA & -1 & nad2 & $13608-14429$ & 822 & ATA/TAG & \\
\hline nad4L & $6013-6246$ & 234 & ATA/TAA & & $\operatorname{trnl}$ & 14430-14485 & 56 & & 187 \\
\hline $\operatorname{trn} W$ & $6247-6301$ & 55 & & & $\cos 3$ & 14673-15449 & 777 & ATA/TAG & \\
\hline $\operatorname{trn} E$ & $6302-6356$ & 55 & & & $\operatorname{trn} N$ & $15450-15501$ & 52 & & \\
\hline$r r n s$ & $6357-7056$ & 700 & & & $\operatorname{trn} G$ & $15502-15557$ & 56 & & 1 \\
\hline $\operatorname{trnS2}$ & 7057-7111 & 55 & & & $\operatorname{trnK}$ & 15559-15615 & 57 & & 4 \\
\hline $\operatorname{trn} Y$ & $7112-7167$ & 56 & & & $\operatorname{trn} C$ & $15620-15673$ & 54 & & \\
\hline nad1 & $7168-8040$ & 873 & ATT/TAA & -5 & $\operatorname{trnF}$ & $15674-15728$ & 55 & & \\
\hline atp6 & $8036-8630$ & 595 & $\mathrm{ATT} / \mathrm{T}$ & & nad6 & 15729-16157 & 429 & TTG/TAG & 326 \\
\hline $\operatorname{trnK}$ & $8631-8690$ & 60 & & & nad4L & $16484-16714$ & 231 & ATT/TAG & 118 \\
\hline $\operatorname{trn} L 2$ & $8691-8745$ & 55 & & & $\cos 2$ & $16833-17513$ & 681 & ATA/TAG & 67 \\
\hline $\operatorname{trnS1}$ & 8746-8798 & 53 & & & nad4 & 17581-18792 & 1212 & ATA/TAA & 9 \\
\hline nad2 & 8799-9623 & 825 & ATT/TAA & 11 & $\operatorname{trn} D$ & 18802-18857 & 56 & & \\
\hline $\operatorname{trnl}$ & 9635-9694 & 60 & & 5 & $\operatorname{trn} M$ & 18858-18911 & 54 & & 42 \\
\hline $\operatorname{trn} R$ & $9700-9752$ & 53 & & 5 & $\operatorname{trn} T$ & 18954-19007 & 54 & & 45 \\
\hline $\operatorname{trn} Q$ & $9758-9811$ & 54 & & & $\operatorname{trnS1}$ & 19053-19111 & 59 & & 11 \\
\hline $\operatorname{trnF}$ & $9812-9865$ & 54 & & & atp6 & 19123-19704 & 582 & ATT/TAG & 75 \\
\hline$c o b$ & 9866-10967 & 1102 & ATA/T & & nad5 & $19780-21240$ & 1461 & ATT/TAA & \\
\hline $\operatorname{trnL1}$ & 10968-11022 & 55 & & & $\operatorname{trnS2}$ & $21241-21293$ & 53 & & 10 \\
\hline $\cos 3$ & 11023-11790 & 768 & ATT/TAA & & $\operatorname{trn} Q$ & $21304-21358$ & 55 & & 2 \\
\hline $\operatorname{trn} N$ & 11791-11844 & 54 & & & $\operatorname{trn} A$ & $21361-21416$ & 56 & & 7 \\
\hline $\operatorname{trnT}$ & 11845-11898 & 54 & & & $\operatorname{trn} P$ & $21424-21476$ & 53 & & \\
\hline nad4 & 11899-13128 & 1230 & ATA/TAA & & $\operatorname{trn} R$ & $21477-21530$ & 54 & & \\
\hline \multirow[t]{2}{*}{$N C R$} & 13129-14778 & 1650 & & & $\operatorname{trn} V$ & 21531-21586 & 56 & & 1 \\
\hline & & & & & $\operatorname{trn} E$ & 21588-21645 & 58 & & \\
\hline
\end{tabular}

*7 bp intergenic sequence between trnE and cox1. 
Table 2 Nucleotide composition of Bursaphelenchus xylophilus (Bx) and Pratylenchus vulnus (Pv)

\begin{tabular}{|c|c|c|c|c|c|c|c|c|c|c|c|c|}
\hline \multirow[t]{2}{*}{ Nucleotide } & \multicolumn{2}{|c|}{ Length (bp) } & \multicolumn{2}{|c|}{ A (\%) } & \multicolumn{2}{|c|}{ C (\%) } & \multicolumn{2}{|c|}{$\mathrm{T}(\%)$} & \multicolumn{2}{|c|}{ G (\%) } & \multicolumn{2}{|c|}{$\mathrm{A}+\mathrm{T}(\%)$} \\
\hline & $B x$ & $\mathrm{Pv}$ & $B x$ & Pv & $\mathrm{Bx}$ & Pv & $\mathrm{Bx}$ & $\mathrm{Pv}$ & $B x$ & Pv & $B x$ & Pv \\
\hline Entire sequence & 14778 & 21656 & 31.8 & 31.8 & 5.4 & 9.8 & 51.7 & 42.1 & 11.1 & 16.3 & 83.5 & 73.9 \\
\hline Protein coding sequence & 10182 & 10002 & 27.1 & 26.7 & 6.3 & 8.7 & 53.4 & 48.4 & 13.2 & 16.2 & 80.5 & 75.1 \\
\hline \multicolumn{13}{|l|}{ Codon position } \\
\hline $1 s t$ & 3394 & 3334 & 28.5 & 27.6 & 6.6 & 9.0 & 46.8 & 43.0 & 18.1 & 20.4 & 75.3 & 70.6 \\
\hline 2nd & 3394 & 3334 & 19.2 & 18.3 & 10.4 & 12.5 & 55.7 & 51.8 & 14.7 & 17.4 & 74.9 & 70.1 \\
\hline $3 r d$ & 3394 & 3334 & 33.5 & 34.4 & 1.9 & 4.4 & 57.7 & 50.3 & 6.8 & 10.9 & 91.2 & 84.7 \\
\hline Ribosomal RNA gene sequence & 1648 & 1581 & 39.1 & 30.2 & 5.0 & 11.5 & 46.2 & 39.2 & 9.7 & 19.1 & 85.3 & 69.4 \\
\hline Transfer RNA gene sequence & 1214 & 1216 & 39.1 & 35.0 & 4.9 & 6.9 & 45.6 & 42.2 & 10.5 & 16.0 & 84.7 & 77.2 \\
\hline Non coding region & 1650 & 7748 & 47.7 & 37.4 & 0.7 & 11.3 & 51.0 & 35.5 & 0.7 & 15.8 & 98.7 & 72.9 \\
\hline
\end{tabular}

ATA as the start codon. Four genes (atp6, nad3, nad4L, and nad5) start with ATT, whereas nad1 and nad6 start with TTG (Table 1). The most commonly used start codon for P. vulnus (ATA) is also the most frequently used in Xiphinema americanum mtDNA (11 of 12 PCGs). More rarely, TTA is used as a start codon in nematodes, for example, Ancylostoma doudenale (cox1), Brugia malayi (nad2) and Steinernema carpocapsae (nad2, nad4, and nad6).

For B. xylophilus, nine genes (cox1, cox3, nad1-nad4, nad4L, nad5 and nad6) terminate with TAA and cox2 uses TAG as its termination codon; atp 6 and $c o b$ are inferred to terminate with incomplete stop codon $\mathrm{T}$. Among these, cox2 is inferred to overlap with $\operatorname{trn} H$ by two nucleotides (AG) and nad1 is also inferred to overlap with atp6 by five nucleotides. The truncated (incomplete) termination codon (terminate with ' $\mathrm{T}$ ') is inferred for the atp6 and cob of B. xylophilus; truncated termination ' $\mathrm{T}$ ' is believed to be completed by polyadenylation [31]. For $P$. vulnus, eight genes (atp6, cox2, cox3, nad2, nad3, nad4L, $n a d 6$, and $c o b$ ) are predicted to terminate with TAG and four (cox1, nad1, nad4, and nad5) with TAA, all without overlapping any adjacent gene boundary. The use of TAA as a termination codon in $P$. vulnus is generally consistent with another Tylenchoidea, $H$. glycines [26], but is in marked contrast to the idiosyncratic codon usage found in the other sequenced member of the same superfamily, $R$. similis in which TAA, the canonical stop codon in the standard invertebrate genetic code, is reassigned to encode Tyr [25].

As in other published nematode mtDNAs, the mitochondrial PCGs of these two species are notably biased toward using amino acids encoded by T-rich codons. The three most frequently used codons have more than two Ts in a triplet (Table 3): in B. xylophilus, TTT (Phe: 19.12\%), TTA (Leu: 13.52\%), and ATT (Ile: 7.66\%); in P. vulnus, TTT (Phe: 14.49\%), TTA (Leu: 11.31\%), and ATT (Ile: 5.64\%). These T-rich codons account for $40.3 \%$ (B. xylophilus) and $31.44 \%$ (P. vulnus) of the total codons used. In addition, there is nonrandom use of synonymous codons; avoidance of $\mathrm{C}$ in the third codon position is pronounced in two- and four-fold degenerate codon families. As an example, there are large differences in the relative frequency of codons for phenylalanine usage between TTT (19.12\%) and TTC (0.53\%) in B. xylophilus and between TTT (14.49\%) and TTC (1.14\%) in P. vulnus. The higher frequency of amino acids encoded by T-rich codons, and unequal synonymous codon usage with bias against $\mathrm{C}$-rich codons is consistent with the high percentage of $\mathrm{A}+\mathrm{T}$ content in the nucleotide composition of PCGs (A+T content of $80.5 \%$ and $75.1 \%$ for B. xylophilus and P. vulnus, respectively; Table 2).

\section{Transfer RNA and ribosomal RNA genes}

Twenty-two discrete nucleotide sequences (ranging from 53 to $60 \mathrm{bp}$ for B. xylophilus and 52 to $59 \mathrm{bp}$ for P. vulnus) were predicted to fold into secondary structures of tRNAs (Additional files 1 and 2), similar to those found in other published nematode mtDNAs [32-35]. The predicted structures of tRNA genes in both species include an amino-acyl stem of seven nucleotide pairs (ntp), a DHU stem of 4 ntp with a loop, an anticodon stem of 5 ntp with a loop, and a TV replacement loop. Twenty of the 22 tRNA genes of both species have a unique feature in that the TYC arm and variable loop are replaced by a TV replacement loop. The two exceptions are the serine tRNAs (trnS1 and trnS2) that lack a DHU arm, but have a TYC stem-loop structure. These features are found in other nematode mtDNAs [22-24,32-35], except for T. spiralis in which some tRNAs have the canonical cloverleaf structures [29]. The small-subunit ribosomal RNA ( $r r n S)$ and large-subunit ribosomal RNA ( $r r n L)$ of each mtDNA were initially identified by comparing with homologous gene sequence of other nematode species. The $r r n L$ (948 bp) and $r r n S$ (700 bp) for B. xylophilus are positioned between $\operatorname{trn} H$ and nad3, and between trnE and trnS2, respectively. The $r r n L$ (895 bp) and $r r n S(686 \mathrm{bp})$ for P. vulnus are positioned between trnL1 and nad3, and between $c o b$ and $\operatorname{trn} Y$, respectively. 
Table 3 Codon usage of 12 protein coding genes of Bursaphelenchus xylophilus (Bx) and Pratylenchus vulnus (Pv) mtDNAs

\begin{tabular}{|c|c|c|c|c|c|c|c|c|c|c|c|}
\hline \multirow[t]{2}{*}{ Codon } & \multirow[t]{2}{*}{$A A$} & \multicolumn{2}{|c|}{ No. } & \multicolumn{2}{|c|}{$\%$} & \multirow[t]{2}{*}{ Codon } & \multirow[t]{2}{*}{$A A$} & \multicolumn{2}{|c|}{ No. } & \multicolumn{2}{|c|}{$\%$} \\
\hline & & $B x$ & $\mathrm{Pv}$ & $B x$ & $\mathrm{Pv}$ & & & $B x$ & Pv & $\mathrm{Bx}$ & $\mathrm{Pv}$ \\
\hline$\pi T$ & Phe & 649 & 483 & 19.12 & 14.49 & TAT & Tyr & 160 & 129 & 4.71 & 3.87 \\
\hline TTC & Phe & 18 & 38 & 0.53 & 1.14 & TAC & Tyr & 14 & 24 & 0.41 & 0.72 \\
\hline TTA & Leu & 459 & 377 & 13.52 & 11.31 & TAA & $*$ & 0 & 0 & 0.00 & 0.00 \\
\hline TTG & Leu & 73 & 107 & 2.15 & 3.21 & TAG & * & 0 & 0 & 0.00 & 0.00 \\
\hline $\mathrm{CT}$ & Leu & 26 & 46 & 0.77 & 1.38 & CAT & $\mathrm{His}$ & 46 & 45 & 1.36 & 1.35 \\
\hline CTC & Leu & 2 & 1 & 0.06 & 0.03 & CAC & His & 0 & 2 & 0.00 & 0.06 \\
\hline CTA & Leu & 12 & 33 & 0.35 & 0.99 & CAA & Gln & 30 & 30 & 0.88 & 0.90 \\
\hline $\mathrm{CTG}$ & Leu & 0 & 8 & 0.00 & 0.24 & CAG & Gln & 8 & 26 & 0.24 & 0.78 \\
\hline ATT & lle & 260 & 188 & 7.66 & 5.64 & AAT & Asn & 146 & 99 & 4.30 & 2.97 \\
\hline ATC & lle & 6 & 13 & 0.18 & 0.39 & $A A C$ & Asn & 8 & 5 & 0.24 & 0.15 \\
\hline ATA & Met & 129 & 166 & 3.80 & 4.98 & AAA & Lys & 85 & 67 & 2.50 & 2.01 \\
\hline ATG & Met & 17 & 19 & 0.50 & 0.57 & AAG & Lys & 14 & 33 & 0.41 & 0.99 \\
\hline GTT & Val & 125 & 143 & 3.68 & 4.29 & GAT & Asp & 60 & 55 & 1.77 & 1.65 \\
\hline GTC & Val & 2 & 8 & 0.06 & 0.24 & GAC & Asp & 6 & 5 & 0.18 & 0.15 \\
\hline GTA & Val & 91 & 78 & 2.68 & 2.34 & GAA & Glu & 48 & 54 & 1.41 & 1.62 \\
\hline GTG & Val & 22 & 19 & 0.65 & 0.57 & GAG & Glu & 26 & 35 & 0.77 & 1.05 \\
\hline TCT & Ser & 85 & 90 & 2.50 & 2.70 & TGT & Cys & 33 & 41 & 0.97 & 1.23 \\
\hline TCC & Ser & 1 & 13 & 0.03 & 0.39 & TGC & Cys & 1 & 0 & 0.03 & 0.00 \\
\hline TCA & Ser & 29 & 38 & 0.85 & 1.14 & TGA & Trp & 50 & 59 & 1.47 & 1.77 \\
\hline TCG & Ser & 3 & 7 & 0.09 & 0.21 & TGG & Trp & 12 & 28 & 0.35 & 0.84 \\
\hline $\mathrm{CCT}$ & Pro & 49 & 41 & 1.44 & 1.23 & CGT & Arg & 25 & 16 & 0.74 & 0.48 \\
\hline CCC & Pro & 1 & 4 & 0.03 & 0.12 & CGC & Arg & 0 & 1 & 0.00 & 0.03 \\
\hline CCA & Pro & 16 & 28 & 0.47 & 0.84 & CGA & Arg & 3 & 13 & 0.09 & 0.39 \\
\hline CCG & Pro & 3 & 4 & 0.09 & 0.12 & CGG & Arg & 3 & 3 & 0.09 & 0.09 \\
\hline $\mathrm{ACT}$ & Thr & 67 & 62 & 1.97 & 1.86 & AGT & Ser & 89 & 86 & 2.62 & 2.58 \\
\hline ACC & Thr & 0 & 13 & 0.00 & 0.39 & $A G C$ & Ser & 4 & 5 & 0.12 & 0.15 \\
\hline$A C A$ & Thr & 18 & 30 & 0.53 & 0.90 & AGA & Ser & 103 & 95 & 3.03 & 2.85 \\
\hline ACG & Thr & 2 & 4 & 0.06 & 0.12 & AGG & Ser & 20 & 35 & 0.59 & 1.05 \\
\hline $\mathrm{GCT}$ & Ala & 61 & 53 & 1.80 & 1.59 & GGT & Gly & 77 & 101 & 2.27 & 3.03 \\
\hline GCC & Ala & 0 & 7 & 0.00 & 0.21 & GGC & Gly & 3 & 8 & 0.09 & 0.24 \\
\hline GCA & Ala & 14 & 20 & 0.41 & 0.60 & GGA & Gly & 51 & 58 & 1.50 & 1.74 \\
\hline GCG & Ala & 5 & 4 & 0.15 & 0.12 & GGG & Gly & 24 & 31 & 0.71 & 0.93 \\
\hline
\end{tabular}

\section{Non-coding regions}

For the B. xylophilus mtDNA, a total of 9 intergenic sequences, ranging from 1 to $1,650 \mathrm{bp}$, were found. Of these, the largest non-coding region (NCR; 1,650 bp), located between nad4 and cox 1 genes, contains four identical repeat units of 147-nt, four identical repeat units of 101-nt, plus three identical repeat units of 56-nt with only a single nucleotide mismatch in the first repeat of the $56-n t$ repeat units. This NCR is extremely A+T-rich (98.7\%), much higher than the entire mtDNA sequence (83.5\%). In $P$. vulnus mtDNA, 24 intergenic sequences were found, ranging from a singleton to 6,847 bp $(8,821$ bp in total), accounting for $40.7 \%$ of the genome sequence. Among these, two non-coding regions (NCRs) are very conspicuous due to their lengths; NCR1 (6,847 bp) between cox1 and trnH, and NCR2 (901 bp) between trnH and $\operatorname{trnL1}$ (Table 1). There are three repeated units of a 494-bp sequence (with only two between-unit nucleotide differences) found in the 5' region of NCR1. The mitochondrial NCR in many metazoans contains a sequence motif for replication origin (the control region) that varies from a few hundred bp to tens of $\mathrm{kb}$, with tandemly 
repeated sequence blocks in a 'head-to-tail' fashion. The presence of lengthy repeated segments in non-coding regions is responsible for exceptionally large mtDNA genome size and often contributes to genome size variation among and within individuals (i.e., size-variant heteroplasmy) and/or species in some other metazoans including American shad [36], bark weevils [37], root-knot nematodes [27], scallops [38] and some mermithid nematodes $[28,39]$. Comparative analysis of size variants might be useful for estimating the genetic structure of populations within species and between closely related species [40].

\section{Mitochondrial phylogeny among major chromadorean groups}

We conducted Bayesian and maximum likelihood phylogenetic analyses of nucleotide (NT) and amino acid (AA) sequence datasets (12 protein-coding genes, 11,784 NT characters, 3,928 AA characters) for 41 nematode species, including the two newly sequenced species. The sequence alignments are deposited in TreeBASE (http:// www.treebase.org [submission ID number: 13610 for the NT and 13609 for the AA]). Phylogenetic relationships were mainly consistent with previous reports based on mitochondrial genome analysis [22-24,35]. Chromadoreans formed a monophyletic group in all analyses with robust nodal support (100\% bootstrap percentage [BP] in ML analyses (Figures 2 and 3) and 0.99-1.0 Bayesian posterior probability [BPP], (Figures 4 and 5). Within the Chromadorea 'clade III' (Ascaridomorpha, Oxyuridomorpha, and Spiruromorpha) as previously recovered from SSU rDNA [7] was not monophyletic, regardless of the dataset analyzed or tree-building method. The position of Oxyuridomorpha within Chromadorea varies among the mtDNA analyses. For the NT dataset, Oxyuridomorpha was sister to the Spiruromorpha (Figures 2 and 4) with high nodal support (89\% BP in ML and $0.98 \mathrm{BPP}$ in $\mathrm{BI})$, but in the AA dataset, Oxyuridomorpha was sister to a large chromadorean clade (excluding Spiruromorpha and Tylenchoidea), with moderate (87\% BP in ML) or strong (1.00 BPP) support (Figures 3 and 5). The relationship of Pristionchus pacificus, the only representative of the free-living infraorder Diplogasteromorpha, differed among analyses. For the NT dataset, $P$. pacificus was nested within certain Rhabditomorpha (sampled Rhabditoidea, i.e., C. elegans, C. briggsae, and $H$. bacteriophora) and this relationship was strongly supported (97\% BP in ML (Figure 2) and 0.99 BPP in BI (Figure 4). For the AA dataset, the position of P. pacificus differed by inference method, with ML (Figure 3) showing $P$. pacificus as sister to the Rhabditoidea clade. In contrast, BI of the AA data (Figure 5) depicted P. pacificus as nested within the sampled Rhabditoidea, with strong support (1.00 BPP).

Gene order pattern in metazoan mitochondrial DNA has often been used as an additional tool for inferring relationships [41-43]. There are some reports of lineagespecific idiosyncratic gene order patterns in metazoans including nematodes (e.g., enoplean nematodes [39], mollusks [44,45], tunicates [46], crustacean arthropods [47]), and these cases illustrate that phylogenetic interpretation of gene arrangement data should be made with great caution. For example, gene order patterns for Enoplean species are not only very diverse, but radical gene rearrangements occur between relatively closely related species [39]. In contrast, mitochondrial gene order of chromadoreans is more conserved with substantial gene order pattern similarity (in most cases only translocations of tRNAs) within groups inferred to be monophyletic based on analysis of mtDNA sequences. With the exception of S. sterocoralis and H. bacteriophora in which substantial idiosyncratic gene arrangements distinguish them from other ordinal members (Figure 6), shared gene order patterns for chromadorean species has been interpreted as an additional indicator of their phylogenetic affinity [22-24]. The highly similar gene arrangement shared among most Rhabditomorpha, Ascaridomorpha, and the few representatives of Diplogasteromorpha and Aphelenchoidea for which data are available, may reflect common ancestry. However, within this clade, gene order data provides little information on relationships due to the high overall similarity.

\section{Phylogenetic relationships of Aphelenchoidea and Tylenchoidea}

One aim of the present study was to assess Tylenchomorpha relationships, and specifically between $B$. xylophilus and species of Tylenchoidea. The hypothesis of Tylenchomorpha monophyly was examined with respect to relationships among chromadorean lineages. The phylogenetic trees inferred from both nucleotide and amino acid sequences are in agreement that Tylenchomorpha is not monophyletic (Figures 2, 3, 4, 5 and Additional files 3 and 4). Instead, B. xylophilus (Aphelenchoididae) was consistently found within the clade consisting of Rhabditomorpha, Panagrolaimomorpha, Diplogasteromorpha, and Ascaridomorpha (Figures 2, 3, 4 and 5), and usually (except Figure 5) "between" Strongyloides stercoralis and Steinernema carpocapsae (the sampled Panagrolaimomorpha). The clade of sampled Tylenchoidea, consisting of Radopholus similis (burrowing nematode), Heterodera glycines (soybean cyst nematode) and Pratylenchus vulnus (walnut root-lesion nematode), was sister to the other sampled Chromadorea in all analyses with very high nodal support (100\% BP in ML (Figure 2) and 0.99 BPP in BI (Figure 4) for the NT dataset and 100\% BP in ML (Figure 3) and 1.00 BPP in BI (Figure 5) for the AA dataset). This result indicates that there is no support from the mtDNA genome tree for a sister-group relationship between Tylenchoidea and B. xylophilus (Aphelenchoididae), or 


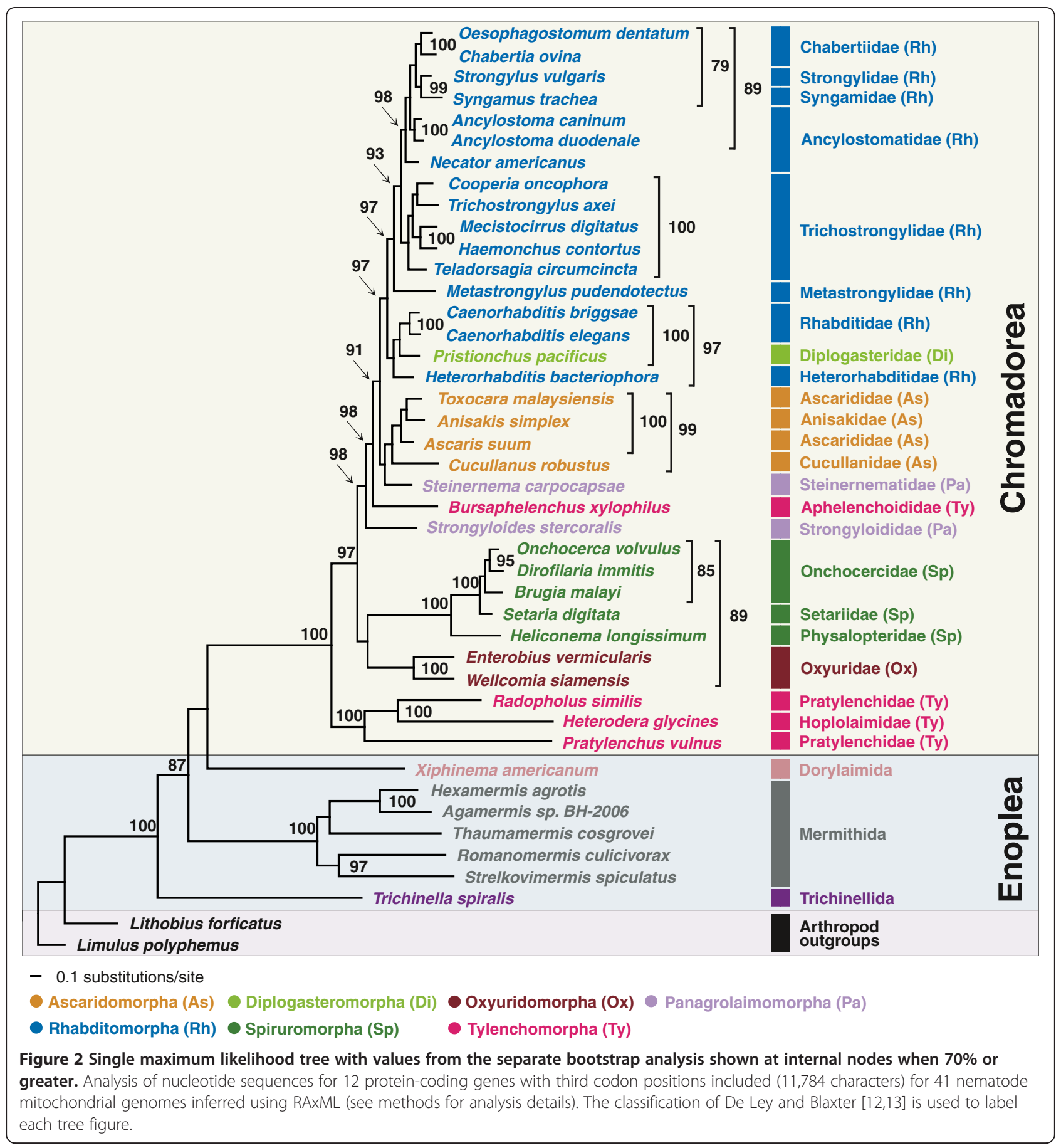

monophyly of Tylenchomorpha as currently defined $[12,13]$. Statistical evaluation of the alternative phylogenetic tree of highest likelihood with the constraint of Tylenchoidea plus $B$. xylophilus monophyly was a significantly worse interpretation of these mtDNA data (Table 4; Additional file 5). Phylogenetic hypotheses based on nuclear SSU rDNA also do not support monophyly of TylenchidaAphelenchoidea [7,9-11], but with different relationships recovered than for mtDNA. In SSU trees including the most compre-hensive sampling for Tylenchomorpha, aphelenchs are polyphyletic, with fungal-feeding taxa such as Aphelenchus spp. (Aphelenchidae) more closely related to plantparasitic Tylenchoidea [7,9,11], and the Aphelenchoididae such as B. xylophilus and Aphelenchoides spp. either more closely related to Panagrolaimomorpha, or nested among a polyphyletic assemblage of panagrolaimomorph taxa [7,911]. Lack of appropriate taxon sampling for mtDNA genomes precludes direct comparison with these SSU results or 


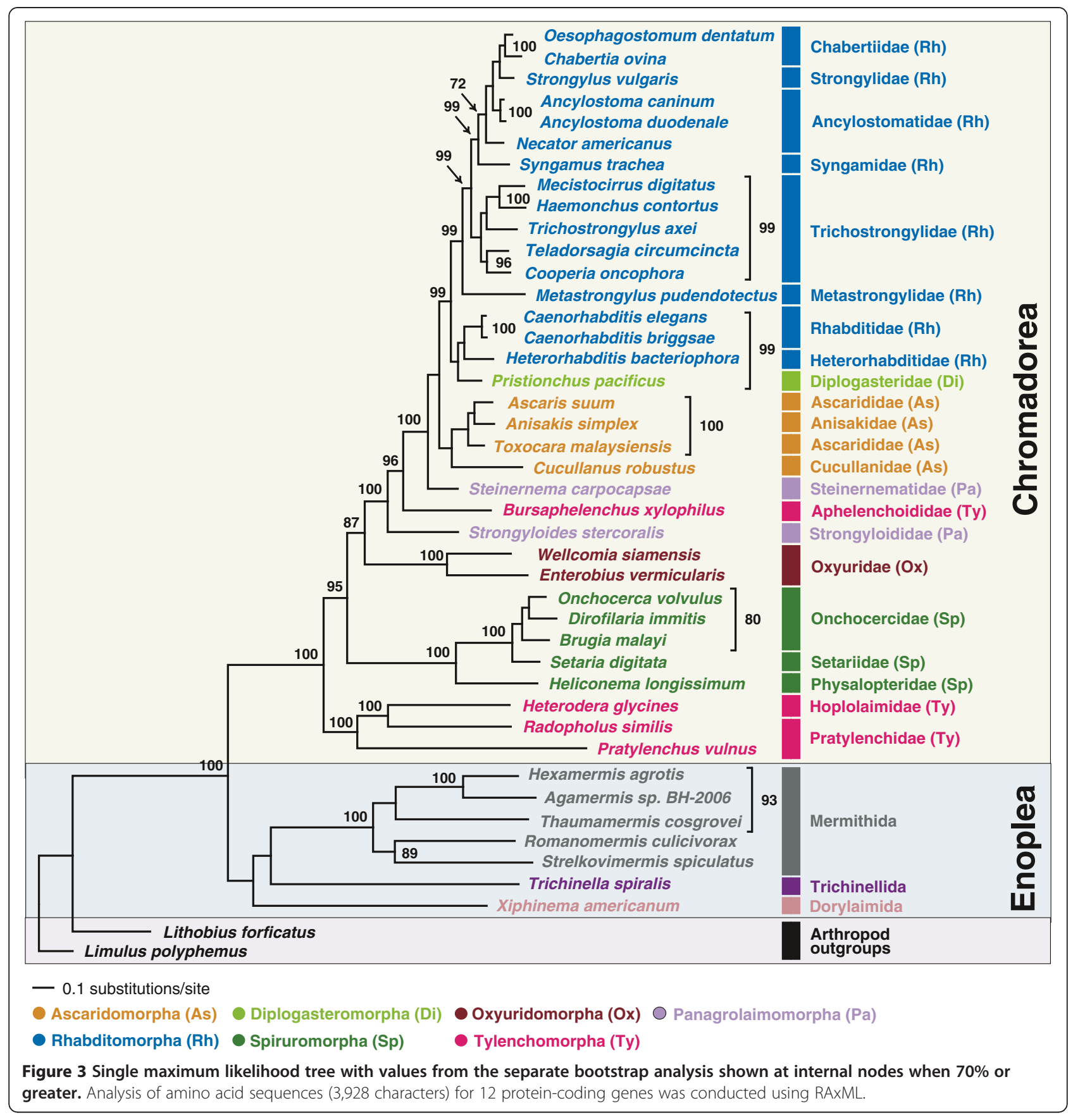

statistical evaluation of certain alternative topologies, highlighting the need to sequence mtDNA genomes representing a greater diversity of Nematoda, especially additional Tylenchina (e.g., cephalobs, panagrolaims, aphelenchs [Aphelenchus spp.]), and other families and superfamilies within Tylenchomorpha. This lack of taxon representation in the mtDNA genome tree may influence the sister-group relationship of Tylenchoidea to other Chromadorea, because adding taxa (new lineages) tends to break long branches, such as those characteristic of $P$. vulnus, $R$. similis, and H. glycines.
In the mtDNA analyses of Tylenchoidea, the two sampled members of Pratylenchidae were not sister taxa, instead, R. similis (Pratylenchidae) was sister to H. glycines (Hoplolaimidae) with very strong support (e.g., 100\% BP in ML (Figure 2) and 0.99 BPP in BI (Figure 4)) for the NT dataset. In terms of mtDNA gene arrangement patterns, $R$. similis and $H$. glycines share gene boundaries for atp6-nad5-trnQ-trnA, rrnL-nad3, trnI-cox3, trnT-nad4, and trnS1-trnC, whereas these two species share less gene order similarity with $P$. vulnus (Figure 6). The monophyly of Tylenchoidea was strongly supported with $P$. vulnus 


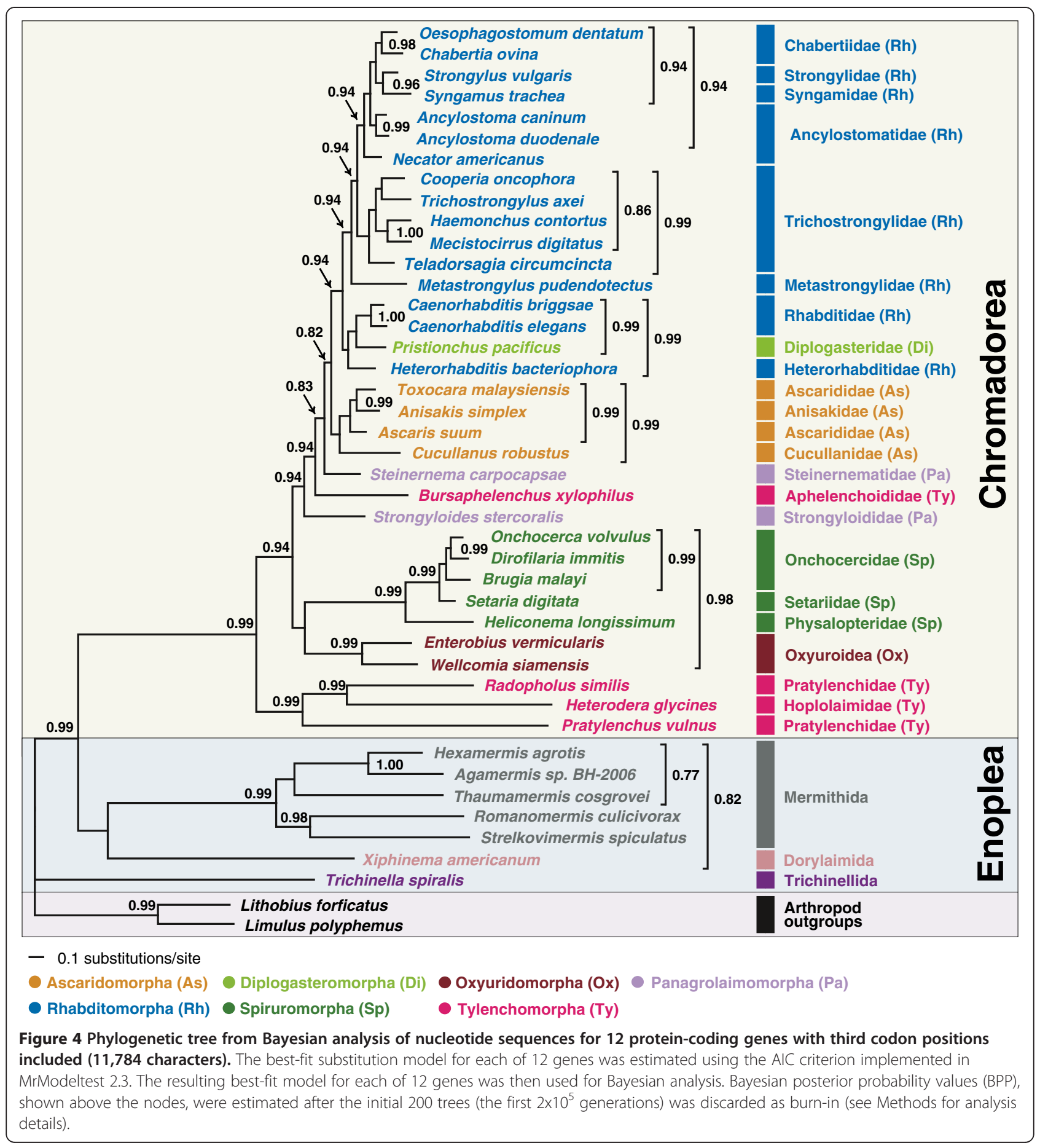

(Pratylenchidae) sister to $R$. similis and $H$. glycines (100\% BP in ML (Figure 2) and 0.99 BPP in BI (Figure 4) for the NT dataset and 100\% BP in ML (Figure 3) and $1.00 \mathrm{BPP}$ in BI (Figure 5) for the AA dataset, respectively). Comprehensive phylogenetic hypotheses based on SSU rDNA sequences also strongly support the monophyly of Tylenchomorpha, but not Pratylenchidae [11]. As in the mtDNA results, analysis of SSU rDNA shows that $R$. similis is more closely related to Heterodera spp. than to P. vulnus or other Pratylenchus spp. [11]. Thus, phylogenetic analysis of both SSU and mtDNA genome data independently show that Pratylenchidae, as traditionally defined, is not a natural group.

Thorne [48] first proposed that aphelenchs and tylenchs should be treated as two superfamilies (Aphelenchoidea and Tylenchoidea) within a separate order (Tylenchida), 


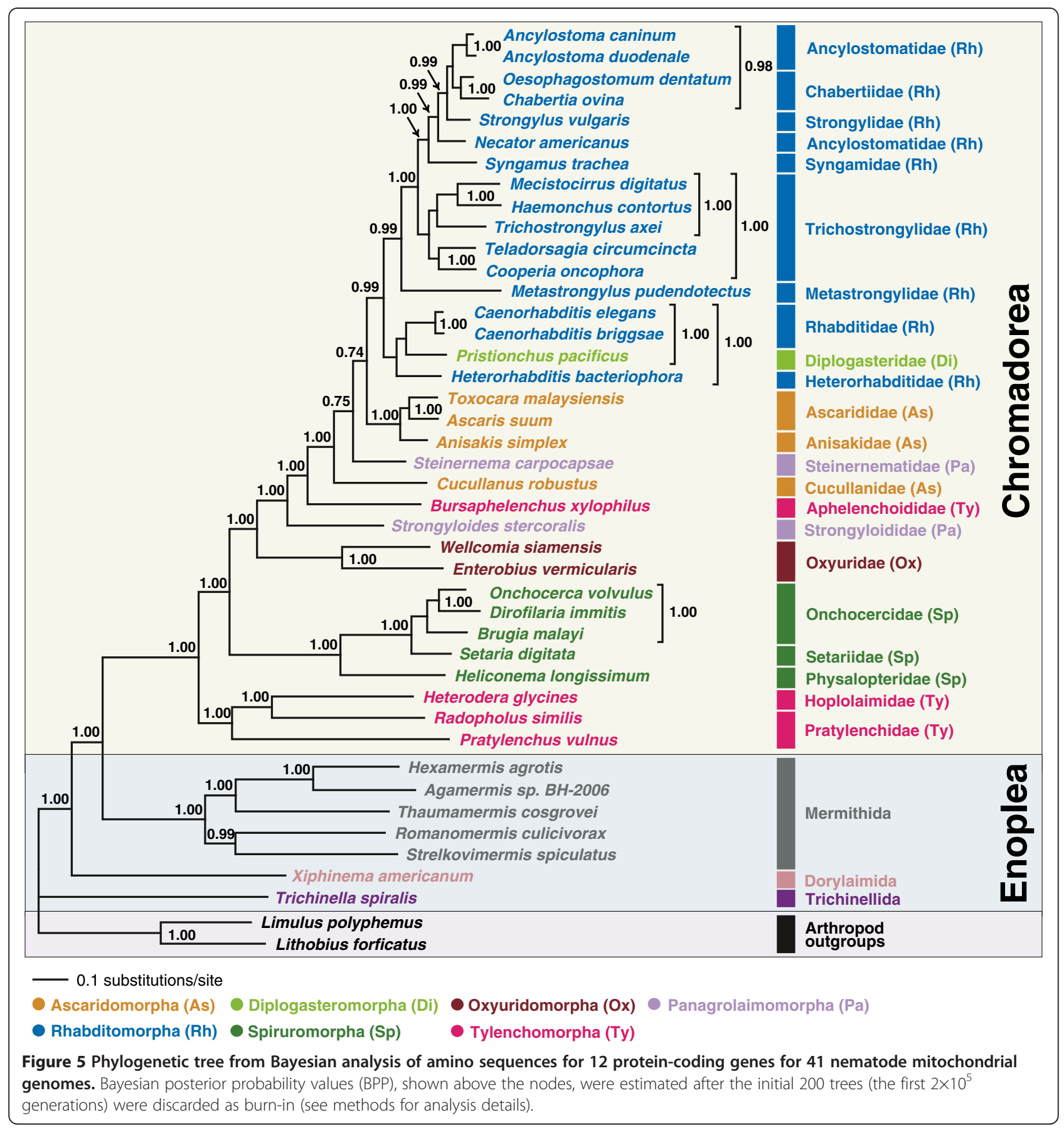

distinguishing this group from other nematodes. Subsequently, taxonomic authorities have offered several different interpretations for the relationships and taxonomic ranking of these nematodes. Many systematists have given special emphasis to morphological similarities shared between aphelenchs and tylenchs, as discerned by light microscopy, such as the protrusible stomatostylet, esophageal structures, and genital structure in females [15,16,18,49-53]. Maggenti [52] hypothesized that plant parasitism in nematodes evolved from fungal-feeding ancestors, and that the progenitors of these taxa were diplogasteromorph-like. Similarly, Poinar [54] emphasized a close relationship between tylenchs, aphelenchs and diplogasteromorphs based on similarities in pharyngeal structure. Later, Maggenti $[18,50]$ recognized tylenchs and aphelenchs as separate orders within a subclass (Diplogasteria). This 'diplogasteromorph origin' was hypothesized on the basis of the general similarity of esophageal structure among tylenchs, aphelenchs, and diplogasteromorphs and inferences concerning development of stoma armature (stylets) from 


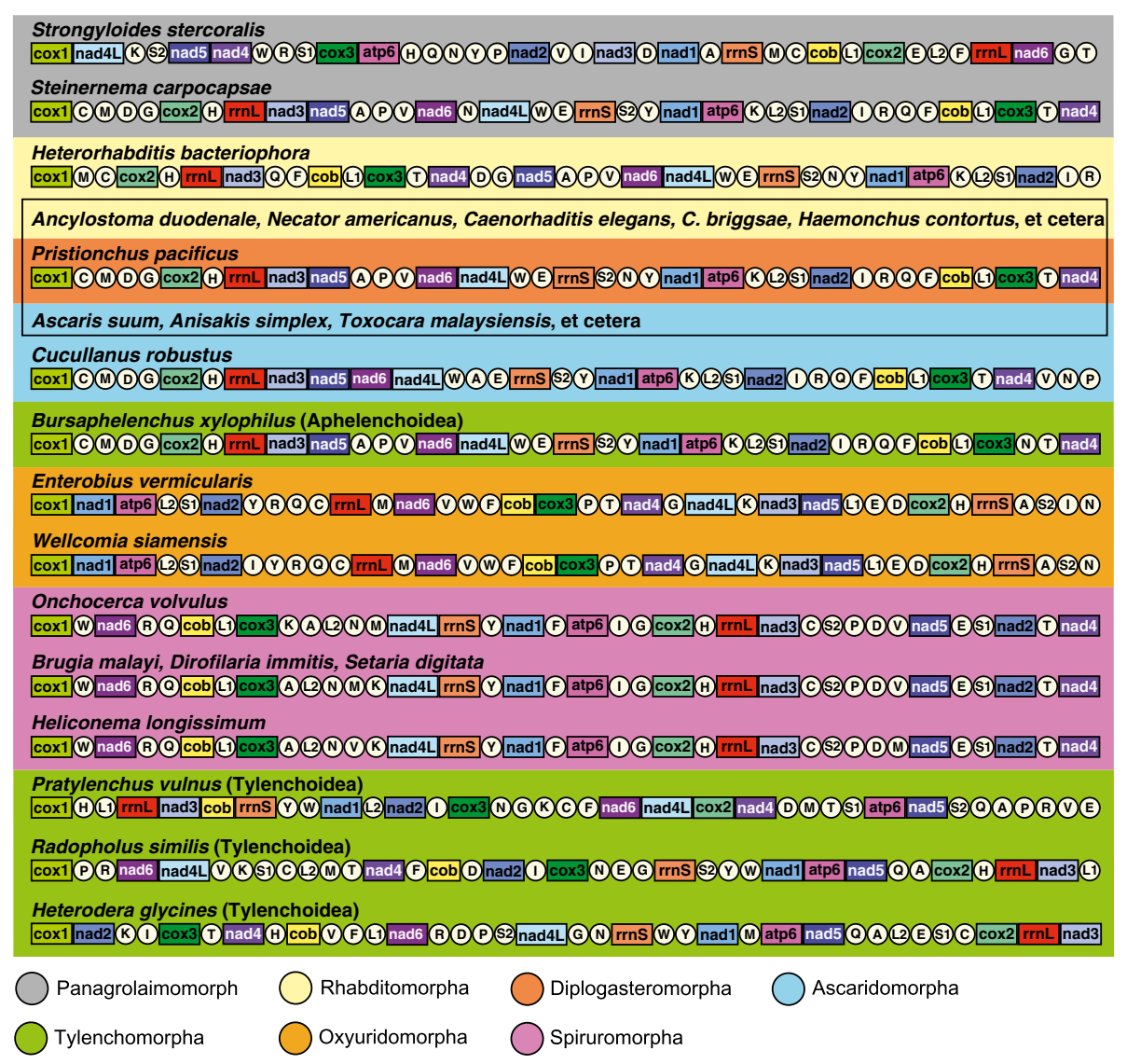

Figure 6 Linearized representation of the mitochondrial gene arrangement for representatives of major chromadorean nematode clades, including two newly determined species (B. xylophilus and $\boldsymbol{P}$. vulnus) in this study. Gene and genome size are not to scale. All genes are transcribed in the same direction (from left to right). The tRNAs are designated by single-letter abbreviation and two leucine and two serine tRNA genes are labeled, according to their anticodon sequence, as L1 (trnL-uag), L2 (trnL-uaa), S1 (trnS-ucu), and S2 (trnS-uga), respectively. The AT-rich non-coding region (NCR) is not indicated. The rectangular box indicates the most common gene arrangement pattern shared among the majority of Rhabditomorpha-Ascaridomorpha members.

Table 4 Results of Shimodaira-Hasegawa ML test (RAxML) for comparisons of alternative tree topologies to the best ML tree (Figure 2) based on all nucleotide data $(11,784$ characters) and partitioned (by gene) analysis

\begin{tabular}{|c|c|c|c|}
\hline $\begin{array}{l}\text { Phylogenetic } \\
\text { hypothesis }\end{array}$ & $\begin{array}{l}\text { Difference } \\
\text { in -InL }\end{array}$ & S.D. & $\begin{array}{l}P \text { value } \\
\text { significant }(0.01)\end{array}$ \\
\hline \multicolumn{4}{|l|}{ Constrained monophyly } \\
\hline 1. Tylenchomorpha & 93 & 30 & yes \\
\hline $\begin{array}{l}\text { 2. Tylenchoidea }+ \\
\text { Diplogasteromorpha }\end{array}$ & 216 & 27 & yes \\
\hline $\begin{array}{l}\text { 3. Aphelenchoididae + } \\
\text { Diplogasteromorpha }\end{array}$ & 105 & 26 & yes \\
\hline $\begin{array}{l}\text { 4. Oxyuridomorpha + } \\
\text { Tylenchoidea }\end{array}$ & 54 & 15 & yes \\
\hline
\end{tabular}

Alternative topologies tested are provided in Additional file 5. stomatal features of certain diplogasteromorphs. Siddiqi $[14,17,19]$ argued that these morphologically similar stylets arose independently in tylenchs and aphelenchs, asserting that plant parasitism in these two groups had separate evolutionary origins, with the former evolved from cephalobomorph/oxyuridomorph-like ancestors and the latter from diplogasteromorph-like ancestors. Our mitochondrial genome phylogeny (Figures 2, 3, 4, 5 and Additional files 3 and 4) did not support a close relationship between diplogasteromorphs (represented by $P$. pacificus) and either tylenchs ( $R$. similis, $H$. glycines, and P. vulnus) or aphelenchs (B. xylophilus). Similarly, oxyuridomorphs (E. vermicularis and W. siamensis) and tylenchs did not form a clade. Tree topology tests indicated that alternative phylogenies constraining a sistergroup relationship between Diplogasteromorpha and Tylenchoidea, Diplogasteromorpha and Aphelenchoidea, or Oxyuridomorpha and Tylenchoidea were significantly worse interpretations of these mtDNA data (Table 4; Additional file 5). Considering the gene arrangement 
pattern among these nematodes (with the exception of S. stercoralis, $H$. bacteriophora, and C. robustus, which have idiosyncratic gene arrangements $[24,35])$ the sampled Rhabditomorpha, Panagrolaimomorpha, Diplogasteromorpha, Ascaridomorpha and B. xylophilus have almost identical patterns with only a translocation of $\operatorname{trn} N$ for B. xylophilus (Figure 6). Indeed, except for the non-coding region (NCR), 33 of the species within the clade containing B. xylophilus share this most common gene arrangement type. In contrast, the gene order of only four blocks comprising two consecutive genes (nad6-nad4L, nad2-trnI, cox3-trnN, and rrnL-nad3) is shared between P. vulnus, R. similis and B. xylophilus. Moreover, only a single block (rrnL-nad3) is shared between B. xylophilus and all three tylenchs (P. vulnus, R. similis and H. glycines).

\section{Conclusions}

In this study, we investigated the phylogenetic relationships of chromadorean nematodes, including new sequences of Tylenchomorpha previously unrepresented in mtDNA genome trees. The mitochondrial genomes of B.xylophilus and P. vulnus are $14,778 \mathrm{bp}$ and $21,656 \mathrm{bp}$, respectively, and identical to all other chromadorean nematode mtDNAs in that they contain 36 genes (lacking atp8) encoded in the same direction. Pratylenchus vulnus has the largest mitochondrial genome of any chromadorean nematode sequenced, due to a large fraction $(54 \%)$ of noncoding sequence. Phylogenetic analyses of nucleotide and amino acid sequence datasets using maximum likelihood and Bayesian methods did not support monophyly of Tylenchomorpha. Instead, B. xylophilus was nested within the Rhabditomorpha+Ascaridomorpha+Panagrolaimomorpha+Diplogasteromorpha clade, and Tylenchoidea (represented by $P$. vulnus, $H$. glycines, and $R$. similis) was sister to all analyzed chromadoreans. Comparison of gene arrangement data was also consistent with the phylogenetic relationships as inferred from sequence data. Statistical comparison of alternative tree topologies revealed that constraining Tylenchomorpha to be monophyletic was a significantly worse interpretation of these mtDNA data. These results confirm previous findings based on nuclear SSU rDNA, indicating that aphelench and tylench plant parasites do not share an exclusive most recent common ancestor, and revealing that certain morphological similarities between these stylet-bearing nematodes must result from convergent evolution.

\section{Methods}

\section{Sampling of specimens}

Live nematodes of $B$. xylophilus were isolated from infected pine trees Pinus densiflora (Jinju, Gyeongnamdo Province, South Korea) and maintained in Botrytiscontaining agar culture plates until they were used for total genomic DNA extraction. The root-lesion nematode
P. vulnus was isolated in Davis, CA, U.S.A. and established and maintained on carrot disk culture in the laboratory. Specimens harvested from disk culture were used for the genomic DNA extraction.

\section{Molecular techniques}

Total genomic DNA was extracted from pooled nematodes of each species using the Qiagen DNA extraction kit according to the manufacturer's protocol. Initially, partial mtDNA fragments were amplified from different regions of mtDNA using universal primers or primer sets designed from the conserved regions of closely related nematode species. Four partial fragments from coxl, rrnS, $c o b$ and cox2 gene regions were PCR-amplified for B. xylophilus using universal primer sets (LCO1490/HCO2198, 12SL1091/12SH1478 and CtybL14841/CtybH15149 for cox $1, \mathrm{rrnS}$ and cob, respectively) and the primer set (COX2-F/R) designed directly from conserved regions of cox2 sequences for chromadorean nematode sequences (See Additional file 6 for primer sequences). For $P$. vul$n u s$, two partial fragments (from $c o b$ and cox 2 gene regions) were amplified using universal primer set CtybL14841/CtybH15149 for $c o b$ and the primer set (COX2-F/R). PCR reactions for both species were carried out in a $20 \mu \mathrm{l}$ reaction volume containing 10 units of Taq polymerase (Roche), $2.5 \mathrm{mM}$ dNTP mixture, 2.5 $\mathrm{mM} \mathrm{MgCl}$, and 20 pmole of each primer with the following amplification conditions: one cycle of the initial denaturation step at $94^{\circ} \mathrm{C}$ for $2 \mathrm{~min}$, followed by 35 cycles of denaturation at $94^{\circ} \mathrm{C}$ for $1 \mathrm{~min}$, primer annealing at $43-48^{\circ} \mathrm{C}$ for $30 \mathrm{~s}$ and elongation at $72^{\circ} \mathrm{C}$ for 1 min. A final extension was performed at $72^{\circ} \mathrm{C}$ for 10 min. The nucleotide sequences obtained from these gene fragments for each of the two species were then used to design species-specific primers for long PCR amplification. Four overlapping long PCR products (ranging from $1.8 \mathrm{~kb}$ to $4 \mathrm{~kb}$; see Additional file 6) covering the entire $B$. xylophilus mtDNA were obtained using the B.xylophilus-specific long PCR primer sets. Similarly, two overlapping long PCR-amplified fragments (ranging from $6 \mathrm{~kb}$ and $15 \mathrm{~kb}$ ) covering the entire mtDNA of $P$. vulnus were obtained using the $P$. vulnus-specific long PCR primer sets. The long-PCR amplification was performed using the Expanded Long Template PCR System (Roche, USA) under the following conditions: 1 cycle of initial denaturation $(2 \mathrm{~min}$ at $\left.93^{\circ} \mathrm{C}\right), 30$ cycles of denaturation-primer annealingelongation $\left(15 \mathrm{~s}\right.$ at $93^{\circ} \mathrm{C}, 30 \mathrm{~s}$ at $50-60^{\circ} \mathrm{C}$, and $13 \mathrm{~min}$ at $68^{\circ} \mathrm{C}$ ), and 1 cycle of the final extension $(10 \mathrm{~min}$ at $68^{\circ} \mathrm{C}$ ). The long PCR products were gel-isolated and ligated using the TOPO XL cloning kit (Invitrogen), as recommended by the manufacturer. Cycle sequencing reactions for each of the cloned PCR products were performed in both directions using a "primer walking" 
strategy, and the sequences of overlapping fragments were double-checked and assembled to obtain the complete sequence of each mitochondrial genome.

\section{Gene annotation and phylogenetic analyses}

Nucleotide sequences were initially analyzed using MEGA4. Each of the twelve mitochondrial protein-coding genes for B. xylophilus and $P$. vulnus was identified by recognizing the open reading frames and comparing the inferred amino acid sequences with those of other nematode species. The start and termination codons were predicted for 12 protein-coding genes by comparison of the amino acid sequences to homologous genes of other Chromadorean nematodes. Ribosomal RNA (rRNA) genes were also identified by comparison with other complete mitochondrial rRNAs of nematodes. The 22 tRNA genes for each mtDNA sequence were identified using the tRNAscan-SE program [55] or by manually inspecting potential secondary structures and anticodon sequences.

For phylogenetic analysis, two types of sequence datasets (nucleotide and amino acid sequences) for the 12 proteincoding genes of the complete mtDNA were obtained from 41 nematode species including B. xylophilus and $P$. vulnus (Additional file 7). Sequence data from two arthropods (Lithobius forficatus and Limulus polyphemus) were also included in the analyses as outgroups. Prior to multiple sequence alignment, nucleotide sequences of the 12 proteincoding genes were translated to amino acid sequences using the invertebrate mitochondrial genetic code. ClustalX with default options [56] was then used to perform multiple alignments of the amino acid sequences. The corresponding nucleotide sequences for these protein-coding genes were aligned based on indels inferred from the protein alignment; the web-based tool RevTrans [57], was used to place the indels in the nucleotide sequences. Phylogenetic analyses of both concatenated nucleotide and amino acid sequence datasets for all 12 protein-coding genes were performed using different tree-building methods (maximum likelihood [ML] and Bayesian inference [BI]). Maximum likelihood (ML) analysis was performed using RAxML 7.0.3 [58] and bootstrap ML analysis was performed using the rapid bootstrap resampling method of RAxML with 1000 replicates, using the CIPRES Science Gateway [59]. The likelihood scores of the competing hypotheses (the best ML tree versus alternative hypothesis) were compared using the Shimodaira-Hasegawa (S-H) test [60]. For both ML and BI, datasets were partitioned by gene for analysis. For BI, MrModeltest 2.3 (nucleotide dataset [61]) and ProtTest 2.4 (amino acid dataset [62]) programs were used to determine the best-fit model for each gene prior to analysis, respectively. Using the CIPRES Gateway, two runs of MrBayes were executed using four MCMC chains and $10^{6}$ generations, sampled every 1,000 generations. Each of the 12 genes was treated as a separate unlinked data partition. Bayesian posterior probability (BPP) values were determined after discarding the initial 200 trees (the first $2 \times 10^{5}$ generations) as burn-in. In addition, ML and BI inference methods were used to analyze the nucleotide data, but with $3^{\text {rd }}$ positions of codons excluded (7,856 characters).

\section{Additional files}

\section{Additional file 1: The predicted secondary structures of 22 tRNAs for Bursaphelenchus xylophilus.}

Additional file 2: The predicted secondary structures of 22 tRNAs for Pratylenchus vulnus.

Additional file 3: Single maximum likelihood tree with values from the separate bootstrap analysis shown at internal nodes when $70 \%$ or greater. Analysis of nucleotide sequences for 12 protein-coding genes with third codon positions excluded (7,856 characters) for 41 nematode mitochondrial genomes inferred using RAxML

(see methods for analysis details).

Additional file 4: Phylogenetic tree from Bayesian analysis of nucleotide sequences for 12 protein-coding genes with third codon positions excluded (7,856 characters). The best-fit substitution model for each of 12 genes was estimated using the AIC criterion implemented in MrModeltest 2.3. The resulting best-fit model for each of 12 genes was then used for Bayesian analysis. Bayesian posterior probability values (BPP), shown above the nodes, were estimated after the initial 200 trees (the first $2 \times 10^{5}$ generations) was discarded as burn-in (see methods for analysis details).

Additional file 5: Nexus file descriptions for alternative topologies tested for results reported in Table 4.

Additional file 6: PCR primer information used in this study.

Additional file 7: The species, taxonomy, and GenBank accession numbers for nematode species used in phylogenetic analyses in this study.

\section{Abbreviations}

AA: Amino acid; atp6 and atp8: Genes for ATP synthase subunits 6 and 8; BI: Bayesian inference; bp: Base pair; BP: Bootstrap percentage; BPP: Bayesian posterior probability; cob: Gene for cytochrome oxidase b; cox1-cox3: Genes for cytochrome oxidase c subunit 1-3; DHU: Dihydrouridine; dNTP: Deoxyribonucleotide triphosphate; kb: Kilo base; LSU: Large subunit nuclear ribosomal DNA; ML: Maximum likelihood; mtDNA: Mitochondrial DNA; nad1-6, and nad4L: Genes for NADH dehydrogenase subunits 1-6 and 4L; NCR: Non-coding region; nt: Nucleotide; NT: Nucleotide; PCR: Polymerase chain reaction; $r r n S$ and $r r n L$ : Genes for small and large mitochondrial ribosomal RNA subunits; SSU: Small subunit nuclear ribosomal DNA; tRNA: Transfer RNA.

\section{Competing interests}

The authors have no competing interests to declare.

\section{Authors' contributions}

TS, JK, SHL, HH, SK, and GSM participated in laboratory work for mitochondrial genome sequencing. JKP designed the study, performed phylogenetic analyses, interpreted the results and drafted the manuscript. SAN also participated in phylogenetic analyses, interpretation of trees, and drafting the manuscript. All authors read and approved the final manuscript.

\section{Acknowledgements}

This work was supported by the National Research Foundation of Korea (NRF) grant funded by the Korean Government (MEST)(2007-0052998) and the Ministry of Education, Science and Technology (2010-0021692; 2011-0025824), and the Ministry of Land, Transport and Maritime Affairs (PM57121 and Marine Mollusk Resource Bank of Korea, MMRBK) to J-K Park. 


\section{Author details}

'Department of Biological Sciences, Inha University, Incheon 402-751, Republic of Korea. ${ }^{2}$ Graduate Program in Cell Biology and Genetics, College of Medicine, Chungbuk National University, Cheongju 361-763, Republic of Korea. ${ }^{3}$ Division of Forest Insect Pests and Diseases, Korea Forest Research Institute, Seoul 130-012, Republic of Korea. ${ }^{4}$ Korea Polar Research Institute, Songdo Techno Park, Yeonsu-gu, Incheon 406-840, Republic of Korea. ${ }^{5}$ Department of Entomology and Nematology, University of California, Davis, CA 95616, USA. ${ }^{6}$ Graduate Program in Cell Biology and Genetics and Department of Parasitology, College of Medicine, Chungbuk National University, Cheongju 361-763, Republic of Korea.

Received: 9 August 2012 Accepted: 11 January 2013

Published: 18 January 2013

\section{References}

1. Golden AM: Classification of the genera and higher categories of the order Tylenchida (Nematoda). In Plant parasitic nematdoes. Volume 1. Edited by Zuckerman BM, Mai WF, Rohde RA. New York/London: Academic Press: 1971:191-232

2. Poinar GO Jr: Nematoda and Nematomorpha. In Ecology and Classification of North American Freshwater Invertebrat. Edited by Thorp JH, Covich AP. New York: Academic Press; 1991:249-283.

3. Baldwin JG, Nadler SA, Adams BJ: Evolution of plant parasitism among nematodes. Annu Rev Phytopathol 2004, 42:83-105.

4. Malakhov W: Nematodes: Structure, Development, Classification, and Phylogeny. Edited by Hope WD. Washington/London: Smithsonian Institution Press; 1994

5. Bridge J, Starr JL: Plant Nematodes of Agricultural Importance: A Color Handbook. London: Academic Press; 2007.

6. Mai WF: Introduction. In Plant Parasitic Nematodes. Volume 1. Edited by Zuckerman BM, Mai WF, Rohde RA. New York/London: Academic Press; 1971:1-8.

7. Blaxter ML, De Ley P, Garey JR, Liu LX, Scheldeman P, Vierstraete A, Vanfleteren JR, Mackey LY, Dorris M, Frisse LM, Vida JT, Thomas WK: A molecular evolutionary framework for the phylum Nematoda. Nature 1998, 392:71-75.

8. Dorris M, De Lay P, Blaxter ML: Molecular analysis of nematode diversity and the evolution of parasitism. Parasitol Today 1999, 15:188-193.

9. Holterman $M$, van der Wurff $A$, van den Elsen $S$, van Megen $H$, Bongers $T$, Holovachov O, Bakker J, Helder J: Phylum-wide analysis of SSU rDNA reveals deep phylogenetic relationships among nematodes and accelerated evolution toward crown clades. Mol Biol Evol 2006, 23:1792-1800.

10. Smythe A, Sanderson MJ, Nadler SA: Nematode small subunit phylogeny correlates with alignment parameters. Syst Biol 2006, 55:972-992.

11. Bert W, Leliaert F, Vierstraete AR, Vanfleteren JR, Borgonie G: Molecular phylogeny of the Tylenchina and evolution of the female gonoduct (Nematoda: Rhabditida). Mol Phylogenet Evol 2008, 48:728-744.

12. De Ley $P$, Blaxter ML: Systematic position and phylogeny. In The Biology of Nematodes. Edited by Lee BL. New York: Taylor; 2002:1-30.

13. De Ley P, Blaxter ML: A new system for Nematoda: combining morphological characters with molecular trees, and translating clades into ranks and taxa. Nematology Monographs and Perspectives 2004 2:633-653.

14. Siddiqi MR: The origin and phylogeny of the nematode orders Tylenchida Thorne, 1949 and Aphelenchida n. ord. Helminth Abstr Ser B 1980, 49:143-170.

15. Lorenzen S: Entwurf eines phylogenetischen systems der freilebenden nematoden. Veröff Inst Meeresforsch Bremerh 1981, 7:1-472.

16. Geraert E: The use of the female reproductive systems in nematode systematics. In Concepts in Nematode Systematics. Edited by Stone AR, Platt HM, Khalil LF. London: Academic Press; 1983:73-84.

17. Siddiqi MR: Tylenchida: Parasites of Plants and Insects. 2nd edition. Wallingford: $C A B \mid ; 2000$.

18. Maggenti AR: Nemata. In Synopsis and Classification of Living Organisms. Edited by Parker SP. New York: McGraw-Hill; 1982:879-929.

19. Siddiqi MR: Evolution of plant parasitism in nematodes. In Concepts in Nematode Systematics. Edited by Stone AR, Platt HM, Khalil LF. London: Academic Press; 1983:113-129.
20. Ragsdale E, Ngo PT, Crum J, Ellisman MH, Baldwin JG: Reconstruction of the pharyngeal corpus of Aphelenchus avenae (Nematoda: Tylenchomorpha), with implications for phylogenetic congruence. Zool J Linn Soc 2011, 161:1-30.

21. Hu M, Gasser RB: Mitochondrial genomes of parasitic nematodesprogress and perspectives. Trends Parasitol 2006, 22:78-84

22. Kim KH, Eom KS, Park JK: The complete mitochondrial genome of Anisakis simplex (Ascaridida. Nematoda) and phylogenetic implications. Int $J$ Parasitol 2006, 36:319-328.

23. Kang S, Sultana T, Eom KS, Park YC, Soonthornpong N, Nadler SA, Park JK: The mitochondrial genome sequence of Enterobius vermicularis (Nematoda. Oxyurida)-an idiosyncratic gene order and phylogenetic information for chromadorean nematodes. Gene 2009, 429:87-97.

24. Park JK, Sultana T, Lee SH, Kang S, Kim HL, Min GS, Eom KS, Nadler SA: Monophyly of clade III nematodes is not supported by phylogenetic analysis of complete mitochondrial genome sequences. BMC Genomics 2011, 12:392.

25. Jacob JEM, Vanholme B, Van Leeuwen T, Gheysen G: A unique genetic code change in the mitochondrial genome of the parasitic nematode Radopholus similis. BMC Research Notes 2009, 2:192.

26. Gibson T, Farrugia D, Barrett J, Chitwood DJ, Rowe J, Subbotin S, Dowton M: The mitochondrial genome of the soybean cyst nematodes, Heterodera glycines. Genome 2011, 54:565-574.

27. Okimoto R, Chamberlin HM, Macfarlane JL, Wolstenholme DR: Repeated sequence sets in mitochondrial DNA molecules of root knot nematodes (Meloidogyne): nucleotide sequences, genome location and potential for host-race identification. Nucleic Acids Res 1991, 19:1619-1626.

28. Hyman BC, Lewis SC, Tang S, Wu Z: Rampant gene rearrangement and haplotype hypervariation among nematode mitochondrial genomes. Genetica 2011, 139:611-615.

29. Lavrov DV, Brown WM: Trichinella spiralis mtDNA: a nematode mitochondrial genome that encodes a putative ATP8 and normally structured tRNAs and has a gene arrangement relatable to those of coelomate metazoans. Genetics 2001, 157:621-637.

30. Wolstenholme DR: Animal mitochondrial DNA: structure and evolution. Int Rev Cytol 1992, 141:173-216.

31. Ojala D, Montoya J, Attardi G: tRNA punctuation model of RNA processing in human mitochondria. Nature 1981, 290:470-474.

32. Okimoto R, Macfarlane JL, Clary DO, Wolstenholme DR: The mitochondrial genomes of two Nematodes, Caenorhabditis elegans and Ascaris suum. Genetics 1992, 130:471-498.

33. Keddie EM, Higazi T, Unnasch TR: The mitochondrial genome of Onchocerca volvulus: sequence, structure and phylogenetic analysis. $\mathrm{Mol}$ Biochem Parasitol 1998, 95:111-127.

34. Hu M, Chilton NB, Gasser RB: The mitochondrial genomes of the human hookworms, Ancylostoma duodenale and Necator americanus (Nematoda. Secernentea). Int J Parasitol 2002, 32:145-158.

35. Hu M, Chilton NB, Gasser RB: The mitochondrial genome of Strongyloides stercoralis (Nematoda)-idiosyncratic gene order and evolutionary implications. Int J Parasitol 2003, 33:1393-1408.

36. Bentzen $P$, Leggett WC, Brown GG: Length and restriction site heteroplasmy in the mitochondrial DNA of American shad (Alosa sapidissima). Genetics 1988, 118:509-518.

37. Boyce TM, Zwick ME, Aquadro CF: Mitochondrial DNA in the bark weevils: size, structure and heteroplasmy. Genetics 1989, 123:825-836.

38. Gjetvaj B, Cook DI, Zouros E: Repeated sequences and large-scale variation of mitochondrial DNA: a common feature among scallops (Bivalvia. Pectinidae). Mol Biol Evol 1992, 9:106-124.

39. Tang S, Hyman BC: Mitochondrial genome haplotype hypervariation within the isopod parasitic nematode Thaumamermis cosgrovei. Genetics 2007, 176:1139-1150.

40. Lunt DH, Whipple LE, Hyman BC: Mitochondrial DNA variable number tandem repeats (VNTRs): utility and problems in molecular ecology. Mol Ecol 1998, 7:1441-1455.

41. Boore $J$, Brown WM: Big trees from little genomes: mitochondrial gene order as a phylogenetic tool. Curr Opin Genetics Deve 1998, 8:668-674.

42. Boore JL: Animal mitochondrial genomes. Nucleic Acids Res 1999, 27:1767-1780.

43. Lavrov DV, Lang BF: Poriferan mtDNA and animal phylogeny based on mitochondrial gene arrangements. Syst Biol 2005, 54:651-659.

44. Boore JL, Medina M, Rosenberg LA: Complete sequences of the highly rearranged molluscan mitochondrial genomes of the scaphopod 
Graptacme eborea and the bivalve Mytilus edulis. Mol Biol Evol 2004, 21:1492-1503.

45. Valles Y, Boore JL: Lophotrochozoan mitochondrial genomes. Integr Comp Biol 2006, 46:544-557.

46. Stach T, Braband A, Podsiadlowski L: Erosion of phylogenetic signal in tunicate mitochondrial genomes on different levels of analysis. Mol Phylogenet Evol 2010, 55:860-870

47. Kilpert F, Podsiadlowski L: The complete mitochondrial genome of the common sea slater, Ligia oceanica (Crustacea, Isopoda) bears a novel gene order and unusual control region features. BMC Genomics 2006, 7:241.

48. Thorne G: On the classification of the Tylenchida, new order (Nematoda. Phasmidia). Proc Helminth Soc Wash 1949, 16:37-73.

49. Paramonov AA: Plant-Parasitic Nematodes: Systematics of Nematodes Superfamily Tylenchoidea. Volume 3. Edited by Skrjabin K. Washington DC: The U.S. Department of Agriculture and the National Science Foundation; 1972

50. Maggenti AR: Nematode higher classification as influenced by species and family concepts. In Concepts in Nematode Systematics. Edited by Stone AR, Platt HM, Khalil LF. London: Academic Press; 1983:25-40.

51. Paramonov AA: A critical review of the suborder Tylenchida (Filipjev, 1934) (Nematoda. Secernentea). Akad Nauk SSSR Trudy Gel'mint Lab 1967, 18:78-101.

52. Maggenti AR: Nemic relationships and the origins of plant parasitic nematodes. In Plant Parasitic Nematodes. Volume 1. Edited by Zuckerman BM, Mai WF, Rohde RA. New York/London: Academic Press; 1971:65-81.

53. Andrássy l: Evolution as a Basis for the Systematization of Nematodes. London: Pitman Publishing; 1976.

54. Poinar GO Jr: The Natural History of Nematodes. Englewood Cliffs, NJ: Prentice Hall; 1983 .

55. Lowe TM, Eddy SR: tRNAscan-SE: a program for improved detection of transfer RNA genes in genome sequences. Nucleic Acids Res 1997, 25:955-964.

56. Thompson JD, Gibson TJ, Plewniak F, Jeanmougin F, Higgins DG: The CLUSTAL $\mathrm{X}$ windows interface: flexible strategies for multiple sequence alignment aided by quality analysis tools. Nucleic Acids Res 1997, 25:4876-4882.

57. Wernersson R, Pedersen AG: RevTrans: multiple alignment of coding DNA from aligned amino acid sequences. Nucleic Acids Res 2003, 31:3537-3539.

58. Stamatakis A: RAxML-VI-HPC: maximum likelihood-based phylogenetic analyses with thousands of taxa and mixed models. Bioinformatics 2006, 22:2688-2690

59. Miller MA, Pfeiffer W, Schwartz T: Creating the CIPRES Science Gateway for inference of large phylogenetic trees. In Proceedings of the Gateway Computing Environments Workshop (GCE). New Orleans; 2010:1-8.

60. Shimodaira H, Hasagawa M: Multiple comparisons of log-likelihoods with applications to phylogenetic inference. Mol Biol Evol 1999, 16:1114-1116.

61. Nylander JAA: MrModeltest v2. Program distributed by the author. Evolutionan Biology Centre, Uppsala University; 2004. Available from http://www.abc.se/ nylander/.

62. Abascal F, Zardoya R, Posada D: ProtTest: Selection of best-fit models of protein evolution. Bioinformatics 2007, 24:1104-1105.

doi:10.1186/1471-2148-13-12

Cite this article as: Sultana et al.: Comparative analysis of complete mitochondrial genome sequences confirms independent origins of plant-parasitic nematodes. BMC Evolutionary Biology 2013 13:12.

\section{Submit your next manuscript to BioMed Central and take full advantage of:}

- Convenient online submission

- Thorough peer review

- No space constraints or color figure charges

- Immediate publication on acceptance

- Inclusion in PubMed, CAS, Scopus and Google Scholar

- Research which is freely available for redistribution

Submit your manuscript at www.biomedcentral.com/submit
C Biomed Central 